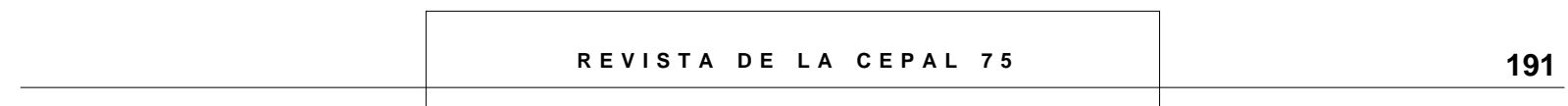

\title{
El empleo en
}

América Latina,

base fundamental

\section{de la política social}

\section{Barbara Stallings \\ Directora \\ División de Desarrollo \\ Económico, \\ CEPAL \\ bstallings@eclac.cl \\ Jürgen Weller \\ Oficial de Asuntos \\ Económicos \\ División de Desarrollo \\ Económico, \\ CEPAL \\ jweller@eclac.cl}

Este artículo analiza las tendencias del mercado de trabajo en América Latina y el Caribe durante el decenio de 1990 y plantea que el empleo debe ser la base de una estrategia de política social para la región. Comienza con un análisis de las expectativas de desempeño del mercado laboral generadas por el proceso de reforma en la región. Luego ofrece una visión general de lo sucedido efectivamente en materia de tasas de participación, generación de empleo, desempleo y salarios. También sugiere algunas razones por las cuales la realidad fue inferior a la esperada. Enseguida examina una nueva hipótesis sobre los diferentes desempeños de los mercados de trabajo en los países del norte y en los del sur. Por último, sobre la base de datos que sostienen la hipótesis, formula recomendaciones de política sobre medidas específicas para unos y otros, y señala políticas aplicables a la región en su conjunto. 


\section{I}

\section{Introducción}

Para ser eficaces, los programas de política social deben partir de una estrategia generadora de empleo, vínculo fundamental entre el desarrollo económico y el desarrollo social. En lo económico, la fuerza de trabajo es uno de los principales factores de producción, y su importancia va en aumento, pues el capital humano es elemento clave para el crecimiento de la economía y de la productividad. Desde el punto de vista social, el empleo es la principal fuente de ingreso de la mayoría de los hogares latinoamericanos. A menos que haya un número suficiente de puestos de trabajo que proporcionen el mínimo necesario para mantener al trabajador y a sus familiares, las políticas sociales se verán agobiadas por la exigencia de satisfacer las necesidades básicas de la población. No podrán así cumplir la función que les corresponde, como complemento del mercado de trabajo, de mejorar el grado de preparación de los trabajadores actuales y potenciales y de suministrar una red de seguridad para quienes no están en condiciones de trabajar. Este es el principio fundamental en que se basa el análisis que ofrecemos en el presente artículo.

Nuestro estudio centra la atención en el decenio de 1990, cuando la mayoría de los países había adoptado el nuevo modelo económico basado en el mercado. Las reformas en que se basó este modelo despertaron grandes expectativas de generación de empleo, con su efecto positivo consiguiente sobre la equidad. En la sección II se pasa revista a estas expectativas y se analizan las razones por las cuales han sido desalentadores los resultados obtenidos hasta ahora. La sección III traza la evolución de los mercados de trabajo de la región a la luz de una serie de indicadores, a saber, las tasas de participación, la generación de empleo total y por sectores, la creación de puestos de trabajo según el tamaño de la empresa y los resultados de todos estos factores para las tasas de desempleo. Además, ofrece información acerca de los salarios y de la brecha salarial entre los trabajadores calificados y los no calificados, que son vínculos importantes entre el comportamiento del mercado de trabajo y la distribución del ingreso. El análisis confirma que en los años noventa se plantearon graves problemas en el frente laboral por el escaso dinamismo de la generación de empleo y el incremento del desempleo. Aunque subieron los salarios medios, creció también la diferencia de las remuneraciones entre los trabajadores calificados y los no calificados.

La sección IV examina una hipótesis, planteada últimamente, de que habría una diferencia sustancial entre la generación de empleo en los países del norte y en los países del sur de la región. Concretamente, postula que la demanda de mano de obra en la industria manufacturera de México y Centroamérica sería mayor que en los países del sur, donde han predominado las industrias de uso intensivo de capital que se dedican a la elaboración de recursos naturales. La información disponible avala esta hipótesis. El empleo, particularmente el empleo industrial, se elevó más rápidamente en los países del norte, en parte por el dinamismo de la producción. A ello hay que agregar, sin embargo, que fueron superiores las elasticidades del empleo en México y Centroamérica.

A partir del análisis anterior, la sección $\mathrm{V}$ presenta una serie de recomendaciones de política para mejorar el panorama del empleo al iniciar el nuevo decenio. Se analiza además la relación entre el empleo y otras políticas sociales y las sinergias entre ellos.

\section{II}

\section{Las reformas y el empleo: las expectativas y la realidad}

En los últimos diez a quince años, la política económica aplicada en América Latina y el Caribe experimentó la mayor transformación que haya registrado desde la Segunda Guerra Mundial. Aplicando una serie de reformas estructurales, un número creciente de países dejaron de ser economías cerradas, dominadas 
por el Estado, y se convirtieron en economías orientadas al mercado y abiertas al resto del mundo. Las reformas comprenden los procesos de liberalización de las importaciones, la liberalización financiera interna e internacional y las privatizaciones, además de la reforma laboral, aunque en esta materia la mayoría de los cambios han sido de hecho y no de derecho. ${ }^{1}$

Fueron muy grandes las expectativas cifradas en el resultado de las reformas, basadas más que nada en estudios que datan de fines de los años setenta y comienzos de los ochenta. ${ }^{2}$ Estos prestaban especial atención al aumento de las tasas de crecimiento mediante la reorientación de la estructura productiva desde el mercado interno (la denominada industrialización basada en la sustitución de importaciones, o modelo ISI) a la producción para el mercado externo. Se suponía que este vuelco se traduciría en una mayor eficiencia a nivel microeconómico, un mejor aprovechamiento de las economías de escala y una moderación de los ciclos de estancamiento y progreso (stop-go) derivados de la escasez de divisas.

Estos estudios también sostenían que al eliminar las distorsiones provocadas por el modelo de sustitución de importaciones se generaría más empleo, en especial para los trabajadores no calificados. Entre los mecanismos que supuestamente relacionaban las reformas con el incremento del empleo citaban principalmente la distribución más eficiente de los recursos, que al facilitar un crecimiento más dinámico generaría más puestos de trabajo. Y esto sucedería aunque la elasticidad del empleo se mantuviera invariable. Además se suponía que la elasticidad del empleo sería más favorable por efecto de los cambios en el patrón de la inversión y en la estructura productiva. Como las ventajas comparativas de América Latina descansaban en la mano de obra no calificada, se pronosticaba que al eliminar el supuesto sesgo en favor del capital la inversión en general y, específicamente, las tecnologías seleccionadas, se volverían más intensivas en su uso

\footnotetext{
${ }^{1}$ La situación en que se encuentran las reformas laborales ha sido objeto de alguna controversia. El BID (1997) sostiene que las reformas han sido escasas. En cambio, para Weller (2000a, cap. 7), ha habido cambios importantes, aunque a menudo no se han incorporado en la legislación.

${ }^{2}$ Entre los primeros estudios en favor de las reformas estructurales figuran los llevados a cabo por Anne Krueger (Krueger, 1978; Krueger y otros (eds.). 1981, y Krueger (ed.). 1982 y 1983) para la National Bureau of Economic Research. El hecho de que esta autora se desempeñara como Economista Jefe del Banco Mundial a comienzos de los años ochenta hacía pesar sus opiniones más allá de los círculos académicos.
}

de la mano de obra. El mayor énfasis en las exportaciones también generaría más puestos de trabajo pues se pensaba que la intensidad del uso de mano de obra en la producción para la exportación era superior a la que correspondía a los productos que competían con las importaciones. Esta conclusión coincidía con el análisis sectorial, según el cual la nueva estrategia comercial favorecería de manera especial la actividad agropecuaria y la industria liviana. Por último, se insistía en que reduciendo el elevado costo de la contratación de trabajadores, se crearían más puestos de trabajo.

Además de los beneficios para el empleo, se esperaba que su expansión ayudaría a mejorar la distribución manifiestamente inequitativa del ingreso, característica de América Latina. ${ }^{3}$ El vínculo más obvio sería la generación de nuevos puestos de trabajo de baja calificación. En la medida en que muchos de estos nuevos empleos se crearían en zonas rurales, ayudarían a mitigar la pobreza en sus focos principales. Asimismo, se preveía que la mayor demanda de mano de obra no calificada influiría positivamente en los salarios relativos de las personas que ya tenían trabajo. En otras palabras, se reducirían las diferencias de salario entre los trabajadores calificados y los no calificados, con lo cual mejoraría la distribución del ingreso. Además, lo más probable es que disminuyera la diferencia entre las utilidades y los salarios; algunas indicaciones señalaban que la protección había elevado las primeras a expensas de los segundos. Por último, al perder importancia el papel del Estado en la producción, se liberarían recursos que podrían destinarse a gastos sociales para favorecer a los grupos más pobres.

Ha aparecido en los últimos tiempos una segunda serie de estudios que examina si se han cumplido las expectativas cifradas en las reformas. En ellas se advierte un grado sorprendente de consenso; en general, concluyen que el crecimiento de los años noventa

\footnotetext{
${ }^{3}$ Aunque no hay duda de que los proponentes de las reformas creían que éstas favorecerían el empleo, no hay tanto acuerdo en cuanto a que se propusieran explícitamente lograr el mejoramiento de la distribución del ingreso. Balassa y otros (1986, pp. 93 a 94) lo hicieron claramente, así como Krueger (ed. 1983, pp. 186-187). Williamson excluyó expresamente el mejoramiento de la distribución del ingreso de las medidas del Consenso de Washington señalando que el Washington de los años de Reagan y Bush no tenía interés en el tema (Williamson, 1990, pp. 413-414, y 1993, p. 1329). Posiblemente la mejor manera de resumirlo sea la conclusión de Bulmer-Thomas de que el nuevo modelo económico "no fue adoptado principalmente" para reducir la pobreza y mejorar la distribución (Bulmer-Thomas, ed. 1997, p. 310).
} 
fue bastante modesto, aunque, evidentemente, superó al de la "década perdida" de los ochenta. Además, la mayoría de los estudios empíricos llega a la conclusión de que las reformas tuvieron un impacto negativo en la generación de empleo y quizá en la equidad. Los datos indican que, en el decenio de 1990, la tasa de crecimiento del empleo fue inferior a la de la segunda mitad de los años ochenta; el desempleo creció; proliferó el empleo en el sector informal; y el alza de los salarios reales favoreció más que nada a los trabajadores calificados. Hay menor acuerdo sobre el impacto de las reformas en la equidad, sosteniendo algunos que influyeron negativamente en la distribución del ingreso y otros que no hay relación entre ellos. Ninguno de los estudios encuentra que se hayan logrado los efectos positivos previstos. ${ }^{4}$
Varias razones explican esta discrepancia entre las expectativas y la realidad, particularmente en materia de empleo. Ante todo, el hecho de que las tasas de crecimiento de los años noventa fueran inferiores a lo previsto significa que las tasas de crecimiento del empleo también se redujeron. Por su parte, las modalidades de la inversión y el crecimiento por sectores muestran que los sectores y empresas menos dinámicos fueron los de uso intensivo de mano de obra, lo que redujo aun más las posibilidades de crecimiento del empleo. En muchos casos las tasas de participación se elevaron, lo que hizo aun más difícil combatir el desempleo. Por último, la hipótesis de que las ventajas comparativas de América Latina radicaban en la mano de obra no calificada resultó equivocada en el conjunto, aunque podría haber sido válida para parte de la región.

\section{III}

\section{La evolución del mercado del trabajo en la región}

En los años noventa, la evolución del mercado del trabajo de América Latina se vio afectada por las reformas y por las tendencias de largo plazo de las economías. Para ampliar el diagnóstico de la sección anterior se examinarán primero las variables de la oferta laboral, según se reflejan en las tasas de participación, y luego la variación de la demanda de mano de obra manifestada en la generación de empleo total y sectorial y en la creación de puestos de trabajo según el tamaño de la empresa. La evolución del desempleo sería el resultado de las presiones de la oferta y la demanda. Los datos relativos a los salarios centran la atención en las tendencias globales y en la brecha salarial entre los trabajadores calificados y los no calificados.

\footnotetext{
${ }^{4}$ Hemos participado en un gran proyecto multianual para evaluar los efectos de las reformas. Al respecto, véase Stallings y Peres (2000), Weller (2000a) y Morley (2000). Otras fuentes importantes son Edwards (1995), Bulmer-Thomas (ed. 1997), BID (1996), Lora y Barrera (1997), Fernández Arias y Montiel (1997), Londoño y Székely (1997), Burki y Perry (1997) y Berry (ed. 1998). Algunas fuentes que tratan especialmente el tema del empleo son Tardanico y Menjívar (eds. 1997), Funkhouser y Pérez Sáinz (1998), Lora y Olivera (1998), Weeks (1999), y varios números de la publicación anual de la огт Panorama laboral de América Latina y el Caribe. Una reseña de esta bibliografía se encuentra en Tuman (2000).
}

Los especialistas concuerdan en que las tendencias de largo plazo del empleo están determinadas por la evolución de la oferta de mano de obra. Las variaciones que experimenta la población económicamente activa (PEA) se explican por los cambios en el tamaño de la población en edad de trabajar (PET) y la medida en que esa población resuelve participar en el mercado de trabajo (la tasa global de participación, o TGP). En América Latina, las últimas dos variables evolucionaron de manera diferente en el período de la posguerra. Por una parte, a medida que avanzó la transición demográfica, disminuyó la tasa anual de crecimiento de la población en edad de trabajar, lo que aflojó la presión sobre el mercado de trabajo. Por la otra, sigue aumentando el grado de participación de la fuerza de trabajo, lo que obedece a la vez a procesos de largo plazo y a fluctuaciones transitorias, sobre todo la mayor participación de las mujeres. Al mismo tiempo, la urbanización, el desarrollo del sistema educativo y el aumento de la cobertura de los sistemas previsionales tendieron a reducir las tasas de participación, ya que las personas se incorporaron más tardíamente a la fuerza de trabajo y se retiraron antes. Desde los años setenta, la tendencia a la disminución de la población en edad de trabajar tuvo un impacto más fuerte que la 
segunda reducción de las tasas de participación, que en los años noventa, en la región en su conjunto, se elevó en 0.2 puntos porcentuales al año, siguiendo la tendencia que había registrado el decenio anterior. El gráfico 1 combina los efectos de los cambios demográficos y de la participación con el fin de mostrar su impacto en el crecimiento de la población económicamente activa, que se redujo de $2.9 \%$ por año en los años ochenta a $2.5 \%$ en los años noventa. ${ }^{5}$

La fuerte correlación entre la oferta laboral y la generación de empleo total entorpece el análisis de la demanda de mano de obra y su posible vinculación con los cambios provocados por las reformas. Para minimizar ese problema, centramos la atención en la evolución entre los asalariados, categoría que guarda una relación más estrecha con la demanda laboral. El cuadro 1 muestra las diferencias entre el empleo total y los asalariados, así como las variaciones en el tiempo; indica el crecimiento económico por decenio en el período de posguerra, la generación de empleo total y asalariado y las elasticidades pertinentes. Dejando de lado los años ochenta, que fueron claramente atípicos, ${ }^{6}$ en los años noventa las elasticidades no fueron muy diferentes de las registradas entre 1950 y 1980. En la medida en que se sintieron en los años noventa los efectos de las reformas, cabe deducir que, a este nivel de agregación, no afectaron -ni positiva ni negativamente- la relación cuantitativa entre el crecimiento del

\section{GRAFICO 1 \\ Variaciones de la oferta de trabajo, $1950-2000^{a}$}

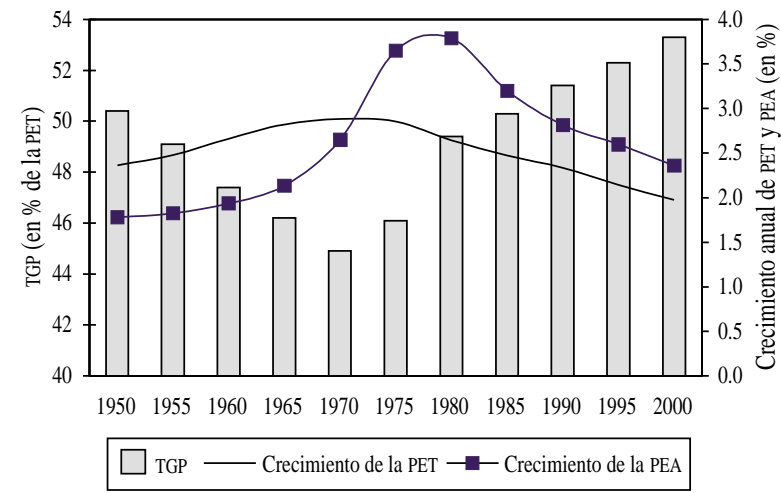

Fuente: Weller (2000, p. 45).

a Basadas en el promedio ponderado de 20 países de América Latina.

PIB y la generación de empleo. Lo que el cuadro destaca respecto del decenio pasado es más bien que las tasas de crecimiento fueron más bajas e incidieron en el menor dinamismo de la generación de empleo, especialmente en el caso de los asalariados.

Como se aprecia en el cuadro 2, las tendencias del empleo a nivel sectorial registraba grandes diferencias en el decenio pasado. Algunas corresponden a procesos

CUADRO 1

Empleo: Crecimiento y elasticidades, 1950-1999a

(Promedio anual ponderado)

\begin{tabular}{lcccc}
\hline Período & $\begin{array}{c}\text { Crecimiento } \\
\text { del PIB }\end{array}$ & $\begin{array}{c}\text { Crecimiento } \\
\text { del empleo }\end{array}$ & $\begin{array}{c}\text { Elasticidad } \\
\text { empleo-producto }\end{array}$ & $\begin{array}{c}\text { Crecimiento del } \\
\text { empleo asalariado }\end{array}$ \\
$1950-59$ & 5.1 & 1.9 & 0.4 & 2.5 \\
$1960-69$ & 5.7 & 2.3 & 0.4 & 2.7 \\
$1970-79$ & 5.6 & 3.8 & 0.7 & 4.7 \\
$1980-89$ & 1.2 & 2.9 & 2.6 & 0.5 \\
$1990-99$ & 3.2 & 2.2 & 0.7 & 0.5 \\
$1950-99$ & 4.2 & 2.6 & 0.6 & 2.0 \\
\hline
\end{tabular}

Fuente: Weller (2000b).

a De los años cincuenta a los setenta, el crecimiento del empleo corresponde al incremento de la fuerza de trabajo. De los cincuenta a los ochenta, las cifras incluyen 20 países; en los noventa, incluyen 17.

5 La compleja interacción de factores relacionados con la oferta y
la demanda se traduce en fluctuaciones de corto plazo en torno a la
tendencia de largo plazo. Por ejemplo, el aumento del desempleo
tiende a elevar la tasa de incremento de la tasa global de participa-
ción, ya que los hogares tratan de compensar la pérdida de ingreso
con el trabajo de un mayor número de sus miembros. Sin embargo,
con el tiempo, la persistencia de un desempleo elevado puede hacer que las personas que pierden la esperanza de encontrar empleo se retiren del mercado de trabajo y, de esta manera, se reduce la tasa de participación.

${ }^{6}$ Las elasticidades especialmente elevadas del decenio de 1980 se debieron al incremento de la oferta de mano de obra en condiciones de crecimiento muy poco dinámicas, pese a lo cual la población económicamente activa aumentó más lentamente que en los años setenta. 
CUADRO 2

Crecimiento del empleo por sectores, 1990-1999a

(Porcentajes)

\begin{tabular}{lcc}
\hline Sector & $\begin{array}{c}\text { Crecimiento } \\
\text { del empleo }\end{array}$ & $\begin{array}{c}\text { Contribución } \\
\text { al total }\end{array}$ \\
\hline Agricultura & -0.4 & -4.3 \\
Industria manufacturera & 1.2 & 8.3 \\
Construcción & 2.8 & 8.0 \\
Comercio, restaurantes y hoteles & 4.0 & 32.7 \\
Electricidad, gas y agua, transporte, & & \\
$\quad$ almacenamiento y comunicaciones & 4.4 & 10.9 \\
Servicios financieros, seguros, bienes & & 12.3 \\
$\quad$ raíces y servicios a empresas & 6.0 & \\
Servicios sociales, comunales & & 34.8 \\
$\quad$ y personales & 2.7 & -2.7 \\
Otros & -2.3 & 100.0 \\
$\quad$ & & \\
Total & 2.2 & \\
\end{tabular}

Fuente: Cálculos de los autores, sobre la base de estadísticas oficiales de los países.

a Promedio ponderado de 17 países.

de larga data. Así, en los años noventa se aceleró la tendencia de largo plazo a la caída del empleo en la agricultura y su incremento en los servicios. Asimismo, parece haber llegado a su fin la fuerte expansión del empleo en el sector manufacturero, que se detuvo a comienzos de los años ochenta para reanudarse a fines de la década. Al mismo tiempo, las reformas fortalecieron muchas de estas tendencias.

Entre 1990 y 1999, el empleo en la agricultura decreció en promedio en $0.4 \%$ anual, pues la demanda laboral de las actividades más dinámicas, por lo general la agricultura de exportación, no fue suficiente para compensar la pérdida de empleo en los sectores menos dinámicos, sobre todo la agricultura campesina. Las reformas contribuyeron de varias maneras a este proceso. La baja de los aranceles estimuló la competencia, al mismo tiempo que se eliminaban los créditos subvencionados. En la medida en que bajaban los precios de la maquinaria agrícola, los empleadores sustituían la mano de obra por equipo.

En los años noventa, el empleo en el sector manufacturero aumentó en América Latina en su conjunto a una tasa anual de sólo $1.2 \%$. Los datos correspondientes al empleo en las empresas medianas y grandes revelan que operaron simultáneamente dos procesos a nivel subsectorial. Por una parte, los subsectores de uso intensivo de mano de obra perdieron participación en comparación con los de uso más intensivo de capital. En los años noventa, las actividades manufactureras de uso intensivo de mano de obra, como los textiles, el vestuario, los productos de cuero y calzado, siguieron perdiendo terreno, mientras que la producción de productos basados en la elaboración de recursos naturales, que requiere un elevado insumo de capital por unidad de producto, mantuvo la participación que había logrado en los años setenta y ochenta. Por otra parte, en los diversos subsectores la incorporación de tecnologías nuevas se tradujo en despidos o en la generación de menor número de puestos de trabajo, incluso en los sectores en que la producción aumentó fuertemente, como el automotriz.

El mayor dinamismo se dio en los servicios, que representaron alrededor del $90 \%$ de la generación neta de puestos de trabajo (cuadro 2, segunda columna). Este sector es muy heterogéneo, pero grosso modo se distinguen en él dos grupos de actividades. El primero - comercio, restaurantes y hoteles, junto con los servicios sociales, comunales y personales - representaba $67 \%$ del total de los puestos de trabajo generados en la región. El segundo — servicios financieros, seguros, bienes raíces y servicios a las empresas-creció aun más rápidamente, igual que los servicios básicos (electricidad, gas y agua, así como transporte, almacenamiento y comunicaciones). Sin embargo, por su baja participación en el empleo total este sector sólo aportó $23 \%$ de los empleos nuevos.

Las reformas económicas cumplieron una función importante en el crecimiento del empleo en el sector de servicios, así como en la polarización que en él se produjo. Pese a que en la mayoría de los países la privatización de los servicios de electricidad y telecomunicaciones se tradujo en gran número de despidos, hubo también un proceso de modernización y expansión, lo que explica que hayan generado empleo. La apertura comercial causó la expansión de los servicios relacionados con los procesos de exportación e importación, mientras que la liberalización financiera creó nuevos servicios financieros y generó empleo. Finalmente, las presiones que se ejercieron para reducir los costos fomentaron el sistema de contratación externa de servicios que hasta entonces eran realizados por las propias empresas manufactureras, lo que explica una parte del vigoroso desarrollo de los servicios a las empresas. Sin embargo, también aumentó el número de empleos de baja calificación en el sector de servicios, que fue la principal fuente de trabajo de las personas que no pudieron encontrar colocación en otros sectores.

Las diferencias no sólo se dieron entre sectores, sino, también, y muy especialmente, en la generación 


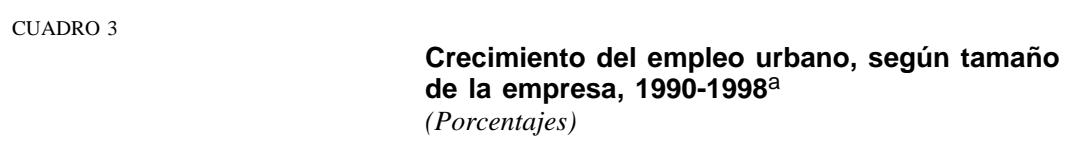

\begin{tabular}{|c|c|c|c|}
\hline \multirow[t]{2}{*}{ Sector } & \multirow{2}{*}{$\begin{array}{l}\text { Tasa anual de } \\
\text { crecimiento del empleo }\end{array}$} & \multicolumn{2}{|c|}{ Contribución al crecimiento } \\
\hline & & Total & Formal/informal \\
\hline Total & 2.9 & 100.0 & \\
\hline Sector informal & 3.9 & 61.0 & 100.0 \\
\hline Trabajadores por cuenta propia & 3.6 & 29.0 & 48.0 \\
\hline Servicio doméstico & 5.2 & 11.0 & 18.0 \\
\hline Microempresas $^{\mathrm{b}}$ & 3.8 & 21.0 & 34.0 \\
\hline Sector formal & 2.1 & 3.9 & 100.0 \\
\hline Sector público & 0.7 & & \\
\hline Empresas privadas & 2.6 & 39.0 & 100.0 \\
\hline Empresas pequeñas ${ }^{c}$ & 3.6 & 9.5 & 25.0 \\
\hline Empresas medianas ${ }^{\mathrm{d}}$ & 2.2 & 12.7 & 32.0 \\
\hline Empresas grandes $\mathrm{e}$ & 2.4 & 16.8 & 43.0 \\
\hline
\end{tabular}

Fuente: OIT (1999a, p. 47).

a Promedio ponderado de 12 países.

b Menos de 6 trabajadores.

c 6 a 20 trabajadores.

d 21 a 100 trabajadores.

e Más de 100 trabajadores.

de empleo según el tamaño de las empresas. De acuerdo con datos de la Organización Internacional del Trabajo (огт), el aumento del número de asalariados del sector privado en los años noventa se dio principalmente en las microempresas (unidades con menos de seis trabajadores) y las empresas pequeñas (seis a veinte trabajadores). Entre 1990 y 1998, el empleo en estos dos grupos aumentó en 3.7\%, frente al $2.3 \%$ de las empresas medianas y grandes y sólo $0.7 \%$ del sector público (cuadro 3 ).

El concepto de sector informal de la orT —ampliamente difundido en los estudios relativos al empleoagrupa en él a las microempresas y a las categorías de trabajo no asalariado (con la excepción de los patrones). ${ }^{7}$ Aunque la definición se basa en el nivel de productividad de las empresas, en la práctica se mide por una variable vicaria que agrupa a las microempresas, los trabajadores por cuenta propia, el servicio doméstico y los trabajadores familiares no remunerados. Como lo indica el cuadro 3, usando esta definición, alrededor de un $60 \%$ de los puestos de trabajo generados en la región corresponden al sector informal. Este concepto de sector informal supone que este tipo de empleo es de baja calidad, por sus condiciones de trabajo deficientes, sus remuneraciones y productividad

${ }^{7}$ Véase en Mezzera (1990) un análisis del sector informal, visto por la oIT. bajas y su falta de equidad legal y social. Desde luego, esto no es totalmente cierto, ya que entre los trabajadores independientes y en algunas microempresas hay buenos puestos de trabajo. Sin embargo, el concepto se sigue utilizando por falta de información sobre las características de estas ocupaciones y en el supuesto de que, en la práctica, la mayoría de ellas son efectivamente precarias.

Más precaria aun es la situación de los desempleados, cuyo número aumentó en América Latina, pese a que el crecimiento del PIB fue superior en los años noventa que en los ochenta. En el período 19801990, el desempleo alcanzó un promedio de $6.6 \%$ y entre 1991 y 2000 subió a $7.2 \%{ }^{8}$ El cuadro 4 indica que la caída generalizada de la tasa de crecimiento del PIB registrada en América del Sur a fines de los años noventa elevó el desempleo a cifras históricas para la subregión y superó los niveles alcanzados durante la crisis de la deuda, a comienzos de los años ochenta. El aumento del desempleo fue muy marcado en Argentina, Colombia, Uruguay y Venezuela, que durante 1999 llegaron a registrar tasas de dos dígitos.

El otro término de la ecuación del mercado laboral son las remuneraciones. Durante el decenio de 1990, los salarios reales medios del sector formal de

\footnotetext{
${ }^{8}$ Las cifras representan el promedio ponderado de 17 países. Si se considera el promedio simple, el incremento fue de 8.3 a $8.6 \%$.
} 
CUADRO 4

Tasas de desempleo, $1980-2000$

(Porcentajes)

\begin{tabular}{|c|c|c|c|c|c|c|c|c|c|c|c|}
\hline & $1980-90$ & 1991 & 1992 & 1993 & 1994 & 1995 & 1996 & 1997 & 1998 & 1999 & $2000^{\mathrm{a}}$ \\
\hline América Latina & 6.6 & 5.7 & 6.1 & 6.2 & 6.3 & 7.2 & 7.7 & 7.3 & 7.9 & 8.7 & 8.4 \\
\hline Argentina ${ }^{b}$ & 5.5 & 6.5 & 7.0 & 9.6 & 11.5 & 17.5 & 17.2 & 14.9 & 12.9 & 14.3 & 15.1 \\
\hline Boliviab $^{b}$ & 7.8 & 5.8 & 5.4 & 5.8 & 3.1 & 3.6 & 3.8 & 4.4 & 6.1 & 8.0 & 7.6 \\
\hline Brasil $^{\mathrm{b}}$ & 5.3 & 4.8 & 5.8 & 5.4 & 5.1 & 4.6 & 5.4 & 5.7 & 7.6 & 7.6 & 7.1 \\
\hline Chile $^{c}$ & 11.9 & 8.2 & 6.7 & 6.5 & 7.8 & 7.4 & 6.4 & 6.1 & 6.4 & 9.8 & 9.2 \\
\hline Colombia $^{\text {b d }}$ & 11.2 & 10.2 & 10.2 & 8.6 & 8.9 & 8.8 & 11.2 & 12.4 & 15.3 & 19.4 & 20.2 \\
\hline Costa Ricab & 6.8 & 6.0 & 4.3 & 4.0 & 4.3 & 5.7 & 6.6 & 5.9 & 5.4 & 6.2 & 5.3 \\
\hline El Salvador ${ }^{b}$ & 9.3 & 7.9 & 8.2 & 8.1 & 7.0 & 7.0 & 7.5 & 7.5 & 7.6 & 6.9 & 6.7 \\
\hline Guatemala $^{\mathrm{c}}$ & 8.0 & 4.2 & 1.6 & 2.6 & 3.5 & 3.9 & 5.2 & 5.1 & 3.8 & $\ldots$ & $\ldots$ \\
\hline Honduras ${ }^{\mathrm{b}}$ & 9.7 & 7.4 & 6.0 & 7.0 & 4.0 & 5.6 & 6.5 & 5.8 & 5.2 & 5.3 & $\ldots$ \\
\hline México $^{b}$ & 4.3 & 2.7 & 2.8 & 3.4 & 3.7 & 6.2 & 5.5 & 3.7 & 3.2 & 2.5 & 2.2 \\
\hline Nicaragua $^{c}$ & 5.3 & 11.5 & 14.4 & 17.8 & 17.1 & 16.9 & 16.0 & 14.3 & 13.2 & 10.7 & 9.8 \\
\hline Panamáb d & 14.5 & 19.3 & 17.5 & 15.6 & 16.0 & 16.6 & 16.9 & 15.5 & 15.2 & 14.0 & 15.2 \\
\hline Paraguay ${ }^{\mathrm{b}}$ & 5.6 & 5.1 & 5.3 & 5.1 & 4.4 & 5.3 & 8.2 & 7.1 & 6.6 & 9.4 & 8.6 \\
\hline Perú $^{\mathrm{b}}$ & 7.4 & 5.9 & 9.4 & 9.9 & 8.8 & 8.2 & 8.0 & 9.2 & 8.5 & 9.2 & 8.5 \\
\hline República Dominicana ${ }^{\mathrm{c} d}$ & $\ldots$ & 19.6 & 20.3 & 19.9 & 16.0 & 15.8 & 16.5 & 15.9 & 14.3 & 13.8 & 13.9 \\
\hline Uruguay $^{b}$ & 8.9 & 8.9 & 9.0 & 8.3 & 9.2 & 10.3 & 11.9 & 11.5 & 10.1 & 11.3 & 13.6 \\
\hline Venezuela $^{\mathrm{c}}$ & 9.3 & 9.5 & 7.8 & 6.6 & 8.7 & 10.3 & 11.8 & 11.4 & 11.3 & 14.9 & 13.9 \\
\hline
\end{tabular}

Fuente: CEPAL, sobre la base de fuentes oficiales de los países.

a Cifras preliminares.

b Zonas urbanas.

América Latina en su conjunto mejoraron, o al menos lograron mantenerse. En Argentina, México, Nicaragua, Perú y Venezuela, en cambio, los salarios fueron más bajos en 2000 que en 1980 (cuadro 5). En muchos países, los salarios reales estuvieron bastante inestables y en algunos casos - Bolivia, Colombia y Costa Rica- disminuyeron a comienzos de los años noventa paro luego volver a subir. En México y Perú se produjo la tendencia opuesta, con un incremento inicial seguido de bajas que en México fueron claramente el resultado de la crisis financiera de 1994 y 1995. Chile fue el único país que registró aumentos sostenidos durante todo el decenio.

De ser cierta la teoría, debería haber una relación de compensación entre los salarios y el volumen de empleo generado, lo que en los años noventa no parece haberse dado. Es decir, el alza de los salarios fue bastante general, pero el comportamiento del empleo y del desempleo varió apreciablemente de un país a otro. ${ }^{9}$ Ello podría explicarse por el hecho de que los mercados laborales de la región no están en equilibrio, pero para poder analizar adecuadamente el fenómeno

\footnotetext{
${ }^{9} \mathrm{El}$ análisis econométrico que figura en Weller (2000a, caps. 4 y 5) da una correlación negativa entre la generación de empleo y los salarios reales, pero el coeficiente no es significativo.
}

c Total nacional.

Incluye el desempleo encubierto. habría que tener mejor información que la disponible actualmente. Los datos sectoriales son particularmente importantes, ya que los mercados laborales de América Latina suelen estar muy segmentados tanto por sectores como por otras características.

Además del salario medio, es importante examinar lo que ocurrió con las distintas categorías de trabajadores. Los estudios indican que la brecha salarial es un vínculo clave entre el mercado de trabajo y la distribución del ingreso. ${ }^{10} \mathrm{Se}$ trata de estudiar la divergencia, si la hubiere, en las tendencias de los salarios de los trabajadores calificados y los de baja calificación. Esto puede hacerse de diversas maneras, siendo la más común el grado de instrucción. En el cuadro 6 se comparan dos versiones de una brecha salarial basada en el nivel educativo en ocho países durante el decenio de 1990: la primera es la diferencia entre las remuneraciones de los profesionales universitarios y las del nivel medio de la muestra, y la segunda la diferencia entre las remuneraciones de los graduados universitarios y las de los que tienen siete a nueve años de estudios (equivalentes a la enseñanza básica completa o quizá un poco más, según la estructura educativa de cada país). En la

\footnotetext{
${ }^{10}$ Bulmer-Thomas (ed., 1997). CEPAL (1997), BID (1998) y Morley (2000).
} 
CUADRO 5

Salario real promedio del sector formal, 1980-2000

$(1990=100)$

\begin{tabular}{|c|c|c|c|c|c|c|c|c|c|c|c|c|}
\hline & 1980 & 1990 & 1991 & 1992 & 1993 & 1994 & 1995 & 1996 & 1997 & 1998 & 1999 & $2000^{\mathrm{a}}$ \\
\hline Argentina ${ }^{b}$ & 128.8 & 99.1 & 100.4 & 101.7 & 100.4 & 101.1 & 100.0 & 99.9 & 99.3 & 99.0 & 100.1 & 101.6 \\
\hline Bolivia $^{c}$ & 57.6 & 87.6 & 82.1 & 85.5 & 91.2 & 98.5 & 100.0 & 100.5 & 106.6 & 110.1 & 117.0 & 118.0 \\
\hline Brasil $^{\mathrm{d}}$ & 94.6 & 104.4 & 88.9 & 87.0 & 95.5 & 96.3 & 100.0 & 107.9 & 110.7 & 110.8 & 105.9 & 104.8 \\
\hline Chile ${ }^{\mathrm{e}}$ & 77.2 & 80.9 & 84.9 & 88.7 & 91.8 & 96.1 & 100.0 & 104.1 & 106.6 & 109.5 & 112.1 & 113.7 \\
\hline Colombia $^{\mathrm{f}}$ & 80.7 & 94.9 & 92.4 & 93.5 & 97.9 & 98.8 & 100.0 & 101.5 & 104.2 & 102.8 & 105.9 & 110.0 \\
\hline Costa Ricag & 104.0 & 89.8 & 85.6 & 89.2 & 98.3 & 102.0 & 100.0 & 97.9 & 98.7 & 104.3 & 109.2 & 110.1 \\
\hline Ecuador $^{\mathrm{h}}$ & 88.3 & 65.4 & 68.4 & 74.2 & 83.5 & 90.9 & 100.0 & 105.4 & 103.0 & 98.9 & 90.7 & 86.4 \\
\hline Guatemala $^{\mathrm{g}}$ & 88.7 & 77.1 & 72.1 & 82.9 & 88.8 & 89.3 & 100.0 & 109.7 & 112.7 & 116.8 & 123.5 & 128.2 \\
\hline Méxicob $^{b}$ & 113.1 & 88.1 & 93.8 & 100.7 & 109.7 & 114.9 & 100.0 & 90.1 & 89.1 & 91.5 & 92.4 & 98.0 \\
\hline Nicaragua ${ }^{\mathrm{I}}$ & 390.8 & 81.8 & 84.5 & 100.5 & 93.3 & 98.2 & 100.0 & 97.9 & 97.7 & 104.9 & 109.6 & 111.3 \\
\hline Paraguay ${ }^{\mathrm{j}}$ & 89.5 & 87.7 & 91.8 & 90.9 & 91.7 & 93.0 & 100.0 & 103.1 & 102.6 & 100.7 & 98.6 & 99.9 \\
\hline Perúk & 265.0 & 85.7 & 98.7 & 95.2 & 94.4 & 109.2 & 100.0 & 95.2 & 94.5 & 92.7 & 90.7 & 91.8 \\
\hline Uruguay & 99.5 & 91.7 & 95.2 & 97.3 & 102.0 & 102.9 & 100.0 & 100.6 & 100.8 & 102.7 & 104.3 & 102.9 \\
\hline Venezuela ${ }^{1}$ & 302.4 & 138.1 & 130.1 & 136.5 & 124.4 & 104.8 & 100.0 & 76.7 & 96.3 & 101.5 & 96.8 & 90.5 \\
\hline
\end{tabular}

Fuente: CEPAL, sobre la base de cifras oficiales para los países.

a Cifras preliminares.

b Industria manufacturera.

c Sector privado de La Paz. La cifra que figura en la columna correspondiente a 1980 se refiere a 1985.

d Trabajadores abarcados por la legislación social y laboral en seis zonas metropolitanas; promedio de 1980 para Rio de Janeiro y São Paulo.

e Hasta abril de 1993, trabajadores asalariados no agrícolas. A partir de mayo de 1993 se utiliza el índice general de los salarios por hora.

f Trabajadores del sector manufacturero.

g Promedio del salario declarado de los trabajadores abarcados por el sistema de previsión social.

h Empresas no agrícolas que ocupan 10 ó más empleados. La cifra que figura en la columna correspondiente a 1980 se refiere a 1985.

i Salario promedio. No incluye remuneraciones en especie u otras prestaciones.

j Asunción.

$\mathrm{k}$ Trabajadores del sector privado en Lima.

1 Trabajadores no manuales y manuales; segundo semestre de cada año. La cifra que figura en la columna correspondiente a 1980 se refiere a 1982.

CUADRO 6

Diferencias de salario según grado de instrucción, decenio de $1990^{\mathrm{a}}$

(Porcentajes)

\begin{tabular}{|c|c|c|c|c|}
\hline \multirow[t]{2}{*}{ País (período) } & \multicolumn{2}{|c|}{$\begin{array}{l}\text { Graduados universitarios comp. con } \\
\text { remuneración media }\end{array}$} & \multicolumn{2}{|c|}{$\begin{array}{l}\text { Graduados universitarios comp. } \\
\text { con 7-9 años instrucción }\end{array}$} \\
\hline & Año inicial ${ }^{b}$ & Año final ${ }^{\mathrm{b}}$ & Año inicial ${ }^{b}$ & Año final ${ }^{b}$ \\
\hline Argentina (1991-97) & 164.3 & 169.6 & 218.3 & 227.9 \\
\hline Bolivia (1989-96) & 235.0 & 292.9 & 251.8 & 506.4 \\
\hline Brasil (1992-97) & 380.2 & 383.5 & 553.2 & 553.3 \\
\hline Chile (1990-96) & 231.6 & 247.9 & 366.1 & 448.6 \\
\hline Colombia (1988-95) & 222.2 & 261.6 & 276.7 & 327.2 \\
\hline Costa Rica (1990-96) & 285.0 & 273.2 & 323.1 & 316.7 \\
\hline México (1991-97) & 182.1 & 232.1 & 160.1 & 302.2 \\
\hline Perú (1991-97) & 220.7 & 275.0 & 321.0 & 403.1 \\
\hline Mediana & 226.9 & 267.4 & 298.9 & 365.2 \\
\hline
\end{tabular}

Fuente: Weller (2000a, p. 167).

a Coeficiente del salario promedio de los grupos especificados.

b Año inicial y final del período indicado para cada país. 
mayoría de los casos, el segundo método dio por resultado una diferencia mayor. La ampliación de la brecha fue pronunciada en la mayoría de los casos, aunque pequeña en Argentina e insignificante en Brasil; sólo en Costa Rica la brecha se achicó.

Otra manera de estudiar las diferencias salariales es comparar los resultados relativos a obreros y empleados. Se dispone de datos sobre varios países, incluso Chile, Colombia, Costa Rica, México y Perú. Casi todos los casos muestran una pauta igual a la obtenida en las comparaciones según el grado de instrucción: los empleados recibieron mayores reajustes de remuneración que los obreros, nuevamente con excepción de Costa Rica. ${ }^{11}$ Por último, hay una diferencia entre las remuneraciones de los trabajadores de las empresas grandes y de las pequeñas: estas últimas se han elevado más lentamente que las primeras (Weller, 2000a, p. 181) No obstante que es más difícil interpretarla, esta tercera diferencia podría incluir también algunos elementos propios de una diferencia en el grado de calificación.

La ampliación de la brecha salarial entre los distintos grados de calificación contradice lo previsto por los que propusieron las reformas. Un análisis teórico apuntaría a que el fenómeno obedecería principalmente a que los precios relativos tienden a favorecer el capital, de menor costo, antes que a la mano de obra, más cara. Esta variación de los precios relativos haría sustituir la mano de obra por capital y, en consecuencia, se registraría una relación capital-trabajo más alta. Sin embargo, de acuerdo con los datos recopilados por Morley respecto de nueve países, las tendencias de los precios relativos no siguieron una trayectoria de acuerdo con esta relación. En los años noventa, la relación se elevó en Brasil, Costa Rica, Chile, y México, bajó en Argentina, Bolivia y Perú y se mantuvo casi invariable en Colombia y Jamaica (Morley, 2000, pp. 99-102).

Si los precios relativos no explican la ampliación de la brecha salarial, la causa quizá radicaría en la reestructuración de las empresas. Por ejemplo, si ocurriera una mayor externalización de los servicios, se podría estimular el empleo de más trabajadores calificados dentro de la propia empresa, mientras que las ocupaciones menos especializadas, como los servicios de cafetería y conexos, los de limpieza y los de seguridad, se contratarían externamente. Esto podría explicar el aumento de la brecha salarial entre las empresas pequeñas y grandes que se produjo en los años noventa. ${ }^{12}$ Otro factor explicativo es la expansión de las actividades terciarias, que en promedio hacen uso más intensivo de mano de obra calificada, y la reducción del peso de los sectores primario y secundario, que usan mano de obra menos calificada. Más importantes aun fueron los procesos internos de mejoramiento del sector de servicios, especialmente de los servicios sociales y comunales, así como de los servicios financieros y a las empresas. Por último, es posible que hayan influido también en algunos países el poder decreciente de los sindicatos, ya que los trabajadores menos calificados fueron quedando excluidos de ellos, así como las políticas relativas al salario mínimo, que a menudo han hecho que éste vaya a la zaga del salario promedio.

\section{IV}

\section{Divergencias entre los países del norte y los del sur}

Aunque en general las tendencias del empleo en América Latina y el Caribe en el decenio de 1990 plantean graves problemas, en los cuadros de la sección anterior se aprecian claras diferencias entre los países. En cierta medida esas diferencias corresponden a los resultados económicos obtenidos por cada país, ya que

11 García-Huidobro (1999), Ramírez y Núñez (1999), Montiel (1999), López (1999), y Saavedra y Díaz (1999). los que registraron tasas de crecimiento más elevadas por lo general fueron los mismos que tuvieron un mejor desempeño en el mercado laboral. El gráfico 2 muestra la relación entre las tasas de crecimiento del PIB y un índice del desempeño del mercado de trabajo para 15 países de América Latina en el período

\footnotetext{
${ }^{12}$ Naturalmente, también se contratan externamente trabajos especializados.
} 
GRAFICO 2

Crecimiento económico y comportamiento del mercado de trabajo, 1990-1998

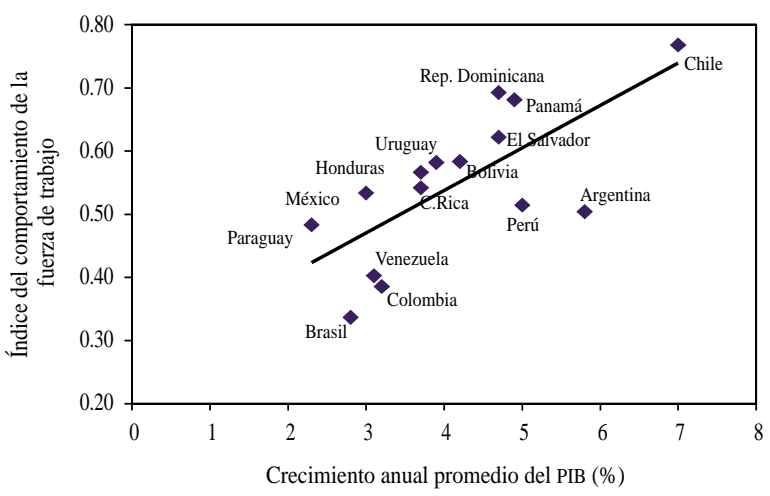

Fuente: Elaboración de los autores.

1990-1998. ${ }^{13}$ Por lo general, los países que crecieron más vigorosamente tuvieron mejores resultados en materia de empleo, desempleo y salarios.

Chile fue el país que registró la más alta tasa de crecimiento económico, lo que influyó positivamente en las cuatro variables laborales: fue así el país que tuvo una mejor evolución en el mercado del trabajo. En cambio, el peor resultado correspondió a Brasil, cuya tasa anual de crecimiento fue la penúltima del grupo. En ese país, el empleo se contrajo fuertemente, lo que se tradujo en un desempleo creciente, pese a que disminuyó la oferta de mano de obra. Argentina fue una excepción, ya que su elevada tasa de crecimiento económico no significó un mejoramiento de la situación laboral. No obstante que el empleo asalariado aumentó, la tasa global de empleo se redujo — particularmente tras la crisis financiera mexicana-y, potenciadas por el incremento de la oferta de mano de obra, a fines de los años noventa las tasas de desempleo se elevaron muy por encima de las registradas al comienzo del decenio.

Además, se ha sugerido la influencia de otro fenómeno. Para la CEPAL, en la región estaría apareciendo una diferencia estructural: la situación de los países del norte (México, Centroamérica y quizá el Caribe) está vinculada con la economía de los Estados

\footnotetext{
13 El índice es un promedio de cuatro subíndices que resumen la evolución de los países en función del desempleo, los salarios reales, la generación de empleo y el aumento del empleo asalariado comparado con el crecimiento general del empleo (como indicador de la demanda). Al mejor y al peor resultado de cada variable se asignó el valor de 1 y 0 puntos, respectivamente.
}

Unidos gracias a la fabricación de productos industriales tradicionales (especialmente textiles) y artículos de mayor contenido tecnológico (artículos electrónicos y automóviles). En los países más pequeños del norte, estos vínculos se han fortalecido por efecto de las industrias maquiladoras, mientras que en México las relaciones de producción son más variadas. En América del Sur, en cambio, la principal fuente de estímulo económico proviene de la elaboración de productos basados en recursos naturales que se exportan a Europa y otros mercados. Entre ellos cabe mencionar el acero, los productos petroquímicos, la celulosa y papel y los alimentos elaborados. Otros productos industriales se destinan al mercado subregional, especialmente el Mercosur. ${ }^{14}$

Al clasificar los tipos de productos que se obtienen en los países del norte y en los del sur según el empuje con que participan en el mercado mundial, se advierte otra diferencia: los productos del grupo de países del norte tienen un comportamiento más dinámico que los del sur. La diferencia se comprueba utilizando un programa informático desarrollado por la CEPAL, que clasifica a los países en cuatro grupos según sus resultados en materia de exportaciones: países cuyas exportaciones principales logran acceder crecientemente al mercado en sectores dinámicos ("estrellas nacientes"); países que aumentan su participación en sectores rezagados ("estrellas menguantes"); países que pierden participación en los sectores dinámicos (de "oportunidades perdidas") y países que pierden participación en los sectores rezagados (de "deterioro competitivo"). El cuadro 7 clasifica a los países de América Latina y el Caribe de acuerdo con estas características, de tal modo que el grupo formado por México y países de Centroamérica aparece principalmente en el cuadrante de las "estrellas nacientes", mientras que los países sudamericanos pertenecen más que nada a la categoría de "estrellas menguantes".

A los efectos del presente trabajo, otro aspecto importante de esta supuesta dicotomía es el hecho de que la producción de la industria maquiladora presentaría una alta intensidad en el uso de mano de obra, mientras que la de productos básicos basada en la elaboración de recursos naturales requiere un uso más intensivo del capital. Esta diferencia en cuanto a la proporción de los factores de producción tiene claras repercusiones para la generación de puestos de trabajo. Los datos disponibles son cuantitativa y cualitativamente limitados, de tal forma que el análisis que

\footnotetext{
14 CEPAL (2000b, vol. 1, cap. 3); véase además Katz (2000).
} 


\begin{tabular}{|c|c|c|}
\hline & $\begin{array}{l}\text { Participación creciente } \\
\text { en el mercado }(\%)\end{array}$ & $\begin{array}{l}\text { Participación decreciente } \\
\text { en el mercado }(\%)\end{array}$ \\
\hline $\begin{array}{l}\text { Productos } \\
\text { dinámicos }\end{array}$ & $\begin{array}{l}\text { "Estrellas nacientes" } \\
\text { República Dominicana (76.0) } \\
\text { México (71.8) } \\
\text { Honduras }(62.3) \\
\text { El Salvador }(54.5) \\
\text { Costa Rica }(46.1) \\
\text { Guatemala }(42.5)\end{array}$ & $\begin{array}{l}\text { "Oportunidades perdidas" } \\
\text { Haití (68.2) }\end{array}$ \\
\hline $\begin{array}{l}\text { Productos } \\
\text { no dinámicos }\end{array}$ & $\begin{array}{l}\text { "Estrellas menguantes" } \\
\text { Paraguay (71.6) } \\
\text { Venezuela (62.0) } \\
\text { Ecuador (58.6) } \\
\text { Chile (54.9) } \\
\text { Uruguay (52.9) } \\
\text { Argentina (48.2) } \\
\text { Colombia (44.4) } \\
\text { Bolivia (43.0) } \\
\text { Brasil (37.7) }\end{array}$ & $\begin{array}{l}\text { "Deterioro competitivo" } \\
\text { Suriname }(64.5) \\
\text { Nicaragua }(48.8) \\
\text { Guyana }(47.3) \\
\text { Perú }(46.0) \\
\text { Panamá }(44.7)\end{array}$ \\
\hline
\end{tabular}

Fuente: CEPAL (2001b, p. 135).

a Los países fueron ubicados en los cuadrantes que corresponden a más de $40 \%$ del valor total de sus exportaciones de mercancías a países de la OCDE.

b Las cifras entre paréntesis corresponden al porcentaje de las ventas de los productos indicados en el cuadrante respecto del total de exportaciones a países de la OCDE.

figura a continuación sólo constituye una primera aproximación.

El cuadro 8 ofrece alguna información básica sobre el comportamiento relativo de países del norte y del sur. Si bien unos y otros presentan rasgos comunes, en especial el predominio de los servicios como fuente de empleo, saltan a la vista dos diferencias. En los países del norte, el crecimiento global del empleo fue casi dos veces mayor que en los del sur $(3.6 \% \mathrm{y}$ $1.6 \%$, respectivamente). Además, a nivel sectorial, el incremento del empleo en los primeros fue más vigoroso o la caída menos pronunciada. Estas diferencias tienen que ver con la correlación positiva entre el aumento de los puestos de trabajo y el crecimiento de la oferta laboral, esto es, el hecho de que la tasa de crecimiento de la población en edad de trabajar haya sido superior en el primer grupo de países. La segunda diferencia surgida del cuadro se relaciona con la demanda de mano de obra: el empleo en el sector manufacturero en los países del norte aumentó a una tasa anual media de $4.3 \%$, esto es, más rápidamente que el empleo total, y representó un $13 \%$ de todos los puestos de trabajo generados. En cambio, en los países del sur, el empleo en el sector manufacturero se contrajo en promedio al $0.1 \%$ por año.

No todos los países siguieron esta misma evolución. En el hemisferio sur, por ejemplo, la generación de puestos de trabajo aumentó rápidamente en Bolivia y Paraguay, tanto en cifras globales, como en el sector manufacturero. Sin embargo, estos empleos correspondieron más bien a la categoría de trabajo por cuenta propia y no a la de trabajo asalariado. Entre los países del norte, Costa Rica no estuvo a la altura de sus vecinos en materia de generación de empleo. Con todo, las diferencias entre ambos grupos de países son significativas y plantean problemas importantes en los países del sur. En cinco de nueve casos (Argentina, Brasil, Colombia, Perú y Uruguay) se produjo una pérdida neta de empleos industriales, mientras que en la mayoría las tendencias globales del empleo fueron abiertamente insatisfactorias, incluso en términos cuantitativos.

Otra diferencia en cuanto a la generación de empleo en los países del norte y los del sur se relaciona con el tipo de empleo. El cuadro 9 clasifica la generación de empleo total en cinco categorías, a saber, asalariados, trabajadores por cuenta propia, servicio doméstico, trabajadores familiares no remunerados, y otros. ${ }^{15}$ En los países del norte, la categoría que creció

\footnotetext{
15 Obsérvese que los cuadros 8 y 9 muestran totales distintos para algunos países, lo que se debe a que la fuente de información es diferente $\mathrm{y}$, en consecuencia, también son diferentes los períodos de tiempo.
} 
CUADRO 8

Crecimiento y contribución del crecimiento del empleo, por sectores, ${ }^{\mathrm{a}}$ 1990-1999

(Porcentajes)

\begin{tabular}{|c|c|c|c|c|c|c|c|c|c|}
\hline País y período & Agricultura & $\begin{array}{c}\text { Industria } \\
\text { manufacturera }\end{array}$ & Construcción & Comercio $^{b}$ & $\begin{array}{l}\text { Servicios } \\
\text { básicos }{ }^{\mathrm{c}}\end{array}$ & $\begin{array}{c}\text { Servicios } \\
\text { financieros }\end{array}$ & $\begin{array}{l}\text { Servicios } \\
\text { sociales }^{\mathrm{e}}\end{array}$ & Otros & Total \\
\hline Argentina & $\ldots$ & -3.1 & 1.0 & 0.3 & 4.0 & 4.9 & 3.0 & $\ldots$ & 1.4 \\
\hline 1991-99 & $\ldots$ & -46.6 & 5.5 & 4.7 & 36.5 & 37.1 & 62.9 & $\ldots$ & 100.0 \\
\hline Bolivia & $\ldots$ & 8.8 & 10.2 & 9.9 & 7.2 & 12.8 & -0.3 & -7.0 & 5.4 \\
\hline $1990-97$ & $\ldots$ & 29.4 & 14.7 & 47.5 & 11.8 & 9.1 & -1.5 & -7.4 & 100.0 \\
\hline Brasil & -0.9 & -0.2 & 2.4 & 2.8 & 3.0 & 5.6 & 2.6 & -1.4 & 1.3 \\
\hline 1992-99 & -18.0 & -1.6 & 11.5 & 26.8 & 8.4 & 14.0 & 62.4 & -3.6 & 100.0 \\
\hline Chile & -1.5 & 0.4 & 3.1 & 3.0 & 3.0 & 7.7 & 2.5 & -3.4 & 1.9 \\
\hline 1990-99 & -12.9 & 3.2 & 11.4 & 29.1 & 12.8 & 24.1 & 35.7 & -3.5 & 100.0 \\
\hline Colombia & -0.5 & -1.4 & 0.7 & 2.1 & 2.3 & 5.0 & 2.8 & -6.6 & 1.1 \\
\hline $1991-99$ & -11.8 & -17.4 & 3.0 & 40.7 & 12.1 & 18.7 & 61.0 & -6.2 & 100.0 \\
\hline Costa Rica & -0.3 & 1.2 & 2.5 & 6.0 & 5.9 & 7.6 & 3.0 & 0.0 & 2.8 \\
\hline $1990-99$ & -2.6 & 7.4 & 5.9 & 38.6 & 12.5 & 11.1 & 27.0 & 0.0 & 100.0 \\
\hline El Salvador & -2.3 & 5.0 & 7.2 & 9.1 & 6.0 & 21.0 & 3.4 & 7.1 & 3.9 \\
\hline 1992-99 & -8.1 & 10.7 & 4.4 & 23.0 & 3.2 & 5.4 & 8.0 & 0.1 & 100.0 \\
\hline Honduras & 2.5 & 7.3 & 4.9 & 7.8 & 3.6 & 10.9 & 5.2 & -2.7 & 4.9 \\
\hline $1990-99$ & 19.9 & 22.3 & 4.9 & 29.5 & 2.0 & 3.7 & 17.9 & -0.2 & 100.0 \\
\hline México & 0.0 & 5.1 & 1.8 & 4.3 & 5.1 & 5.6 & 3.8 & -0.6 & 3.1 \\
\hline 1991-99 & 0.2 & 28.8 & 3.4 & 26.4 & 7.5 & 6.0 & 28.1 & -0.4 & 100.0 \\
\hline Panamá & -1.6 & 3.7 & 15.4 & 5.6 & 4.0 & 9.7 & 3.1 & 12.2 & 3.7 \\
\hline 1991-99 & -9.6 & 9.6 & 20.8 & 32.4 & 9.0 & 13.6 & 23.4 & 0.8 & 100.0 \\
\hline Paraguay & 2.8 & 4.9 & 0.5 & 10.4 & 7.8 & $\ldots$ & 8.4 & -32.7 & 5.2 \\
\hline $1992-99$ & 17.6 & 11.7 & 0.6 & 35.3 & 6.5 & $\ldots$ & 37.2 & -8.9 & 100.0 \\
\hline Perú & $\ldots$ & -0.1 & 7.4 & 5.7 & 10.8 & 12.3 & 0.2 & $\ldots$ & 3.8 \\
\hline 1990-97 & $\ldots$ & -0.6 & 9.9 & 44.1 & 16.5 & 16.5 & 1.7 & $\ldots$ & 100.0 \\
\hline Rep. Dominicana & 1.6 & 3.1 & 14.4 & 6.3 & 6.0 & -5.4 & 1.1 & -17.0 & 3.5 \\
\hline 1991-99 & 8.9 & 15.6 & 19.5 & 42.7 & 12.1 & -2.9 & 7.6 & -3.6 & 100.0 \\
\hline Uruguay & $\ldots$ & -4.0 & 1.8 & 0.4 & 1.0 & 2.9 & -0.7 & 1.1 & -0.5 \\
\hline $1990-99$ & $\ldots$ & -138.3 & 23.7 & 12.2 & 12.0 & 29.6 & -29.6 & 11.5 & 100.0 \\
\hline Venezuela & 1.0 & 2.0 & 3.9 & 6.0 & 4.2 & 2.3 & 3.4 & -0.8 & 3.5 \\
\hline 1990-99 & 3.2 & 8.4 & 8.5 & 39.8 & 8.8 & 3.8 & 27.7 & -0.2 & 100.0 \\
\hline América Latina & -0.3 & 1.2 & 2.8 & 4.0 & 4.4 & 6.0 & 2.8 & -2.1 & 2.2 \\
\hline $\begin{array}{l}\text { (promedio } \\
\text { ponderado) }\end{array}$ & -4.1 & 8.3 & 7.8 & 32.7 & 10.8 & 12.3 & 34.8 & -2.4 & 100.0 \\
\hline América Latina & -0.1 & 1.6 & 2.8 & 5.8 & 4.1 & 6.6 & 3.0 & -1.1 & 3.5 \\
\hline (mediana) & -1.2 & 9.6 & 5.9 & 32.4 & 8.8 & 8.6 & 33.4 & -0.3 & 100.0 \\
\hline Países del norte & -0.1 & 4.3 & 6.0 & 6.1 & 5.5 & 8.6 & 3.3 & -0.3 & 3.6 \\
\hline (mediana) & -1.2 & 13.2 & 5.4 & 30.9 & 8.2 & 5.7 & 27.6 & -0.1 & 100.0 \\
\hline Países del sur & -0.5 & -0.1 & 3.1 & 5.7 & 4.2 & 6.7 & 3.3 & -3.4 & 1.9 \\
\hline (mediana) & -11.8 & -0.6 & 9.9 & 35.3 & 12.1 & 17.6 & 48.3 & -3.5 & 100.0 \\
\hline
\end{tabular}

Fuente: Cálculos de los autores, sobre la base de estadísticas oficiales de los países.

a El primer renglón correspondiente a cada país se refiere al crecimiento anual del empleo en el período indicado; el segundo señala la contribución de cada sector al empleo total generado en el período. Los datos corresponden al total nacional, salvo Argentina (zonas urbanas), Bolivia (capitales de departamento y El Alto), Perú (Lima Metropolitana). Obsérvese que los renglones de América Latina y los países del norte y del sur no suman el total porque representan las medianas de las columnas.

b Incluye hoteles y restaurantes.

c Electricidad, gas y agua, transporte, almacenamiento y comunicaciones.

d Incluye seguros, servicios comerciales y bienes inmuebles.

e Incluye servicios comunales y personales. 
CUADRO 9

Crecimiento y contribución del empleo al crecimiento, según categoría de trabajo, años noventa ${ }^{a}$

(Porcentajes)

\begin{tabular}{|c|c|c|c|c|c|c|}
\hline $\begin{array}{l}\text { País } \\
\text { período }\end{array}$ & Asalariados & $\begin{array}{l}\text { Trabajadores por } \\
\text { cuenta propia }\end{array}$ & $\begin{array}{l}\text { Servicio } \\
\text { doméstico }\end{array}$ & $\begin{array}{l}\text { Trabajadores } \\
\text { familiares no } \\
\text { remunerados }\end{array}$ & Otros & Total \\
\hline Argentina & 1.8 & -1.0 & 2.3 & \multirow[t]{2}{*}{$\ldots$} & 0.9 & 1.1 \\
\hline $1991-97$ & 100.7 & -20.0 & 14.7 & & 4.5 & 100.0 \\
\hline Bolivia & 4.7 & 5.5 & -2.9 & 11.6 & 16.1 & 5.5 \\
\hline $1990-97$ & 41.4 & 34.7 & -2.8 & 12.3 & 14.4 & 100.0 \\
\hline Brasil & 1.1 & 1.5 & 3.8 & -1.9 & 3.1 & 1.2 \\
\hline $1992-97$ & 49.0 & 34.2 & 22.5 & -15.7 & 10.0 & 100.0 \\
\hline Chile & 3.3 & 2.4 & -0.6 & -1.9 & 0.2 & 2.5 \\
\hline 1990-1997 & 84.1 & 22.4 & -1.4 & -15.7 & 0.3 & 100.0 \\
\hline Colombia & 1.1 & 4.0 & 0.1 & -7.5 & -1.4 & 1.4 \\
\hline $1991-97$ & 43.8 & 92.3 & 0.2 & -31.3 & -5.0 & 100.0 \\
\hline Costa Rica & 2.7 & 2.8 & 2.8 & -4.4 & 7.8 & 2.7 \\
\hline $1990-97$ & 64.6 & 20.0 & 4.4 & -6.7 & 17.7 & 100.0 \\
\hline El Salvador & 5.8 & 3.1 & 3.5 & -1.9 & -4.4 & 3.4 \\
\hline 1992-97 & 83.6 & 26.3 & 4.4 & -5.1 & -9.2 & 100.0 \\
\hline Honduras & 4.4 & 4.9 & 4.2 & 3.8 & 15.8 & 4.8 \\
\hline $1990-97$ & 40.6 & 38.1 & 3.5 & 9.9 & 7.9 & 100.0 \\
\hline México & 4.0 & 4.0 & 8.4 & 3.0 & -5.9 & 3.4 \\
\hline $1991-97$ & 62.7 & 28.2 & 9.1 & 11.3 & -11.2 & 100.0 \\
\hline Panamá & 5.0 & 5.0 & 4.0 & -2.3 & -13.1 & 4.0 \\
\hline $1991-97$ & 70.8 & 36.6 & 5.8 & -2.4 & -10.7 & 100.0 \\
\hline Paraguay & 2.9 & 6.3 & 8.5 & 20.4 & 11.5 & 6.3 \\
\hline $1992-97 / 98$ & 19.6 & 37.2 & 8.9 & 25.5 & 8.8 & 100.0 \\
\hline Perú & 1.7 & 5.3 & 1.7 & \multirow{2}{*}{$\ldots$} & \multirow[t]{2}{*}{$\ldots$} & 3.8 \\
\hline $1991-97$ & 18.4 & 81.0 & 0.6 & & & 100.0 \\
\hline Rep. Dominicana & 3.6 & 0.8 & \multirow[t]{2}{*}{$\ldots$} & 8.0 & -2.0 & 1.9 \\
\hline $1991-96$ & 79.3 & 14.5 & & 12.7 & -6.4 & 100.0 \\
\hline Uruguay & 0.8 & 1.6 & \multirow[t]{2}{*}{$\ldots$} & -0.3 & -2.0 & 0.8 \\
\hline $1991-97$ & 77.0 & 37.8 & & -0.5 & -14.3 & 100.0 \\
\hline Venezuela & 2.7 & 8.2 & \multirow[t]{2}{*}{$\ldots$} & -10.0 & 0.2 & 3.8 \\
\hline $1990-97$ & 46.8 & 57.5 & & -4.6 & 0.3 & 100.0 \\
\hline \multirow{2}{*}{$\begin{array}{l}\text { América Latina } \\
\text { (promedio ponderado) }\end{array}$} & 2.2 & 2.2 & 3.0 & 3.8 & 0.2 & 2.2 \\
\hline & 52.7 & 38.2 & 9.1 & -0.4 & 0.4 & 100.0 \\
\hline \multirow{2}{*}{$\begin{array}{l}\text { América Latina } \\
\text { (mediana) }\end{array}$} & 2.7 & 4.0 & 3.2 & -1.9 & 0.2 & 3.4 \\
\hline & 62.1 & 34.7 & 3.5 & -1.5 & 0.3 & 100.0 \\
\hline \multirow{2}{*}{$\begin{array}{l}\text { Países del norte } \\
\text { (mediana) }\end{array}$} & 4.2 & 3.6 & 4.0 & 0.6 & -3.2 & 3.4 \\
\hline & 67.7 & 27.5 & 4.4 & 3.7 & -7.8 & 100.0 \\
\hline \multirow{2}{*}{$\begin{array}{l}\text { Países del sur } \\
\text { (mediana) }\end{array}$} & 1.8 & 4.0 & 1.7 & -1.9 & 0.6 & 2.5 \\
\hline & 46.8 & 37.2 & 0.2 & -2.6 & 2.4 & 100.0 \\
\hline
\end{tabular}

Fuente: Cálculos de los autores, sobre la base de estadísticas oficiales de los países.

a La primera fila correspondiente a cada país se refiere al crecimiento anual del empleo en el período indicado; la segunda señala la contribución de cada sector al empleo total generado en el período. Los datos corresponden al total nacional, salvo Argentina (zonas urbanas), Bolivia (capitales de departamento y El Alto), Perú (Lima Metropolitana). Obsérvese que para América Latina y los países del norte y del sur las filas no suman el total porque representan las medianas de las columnas. 
más rápidamente fue la de los asalariados, con una tasa anual media de $4.2 \%$, que representaba dos tercios de los nuevos puestos de trabajo generados. En cambio, en los países del sur, el trabajo asalariado sólo aumentó $1.8 \%$ al año, lo que representa menos de la mitad de los empleos nuevos. La alternativa fue el trabajo independiente, que creció más dinámicamente en el sur que en el norte $(4.0 \%$ y $3.6 \%$, respectivamente), pese a que en términos globales el empleo aumentó con mayor rapidez en el norte. Como proporción del total de puestos de trabajo generados, en los países del norte el trabajo por cuenta propia representó un $27 \%$, comparado con $37 \%$ en los del sur. Las diferencias en cuanto a la importancia del empleo asalariado se vinculan con las disparidades de la demanda laboral, que aumentaba más rápidamente en el norte.

Las diferencias respecto de la demanda laboral aconsejan volver a examinar la relación entre el crecimiento del PIB y el crecimiento del empleo. En el gráfico 2 veíamos que el comportamiento del mercado de trabajo estaba correlacionado positivamente con las tasas de crecimiento del PIB. Sin embargo, los resultados obtenidos por los países del sur en su conjunto fueron menos satisfactorios que lo que cabía prever por la expansión del $\mathrm{PIB}$, de tal modo que en el gráfico 2 la mayoría, aunque no todos, se sitúan por debajo de la línea de regresión, mientras que la totalidad de los del norte quedan por encima.

Otra manera de analizar la relación entre el crecimiento y la generación de empleo en los distintos países y subregiones es calcular las elasticidades del empleo. El cuadro 10 muestra la situación en que se encontraba la región en los años noventa, que apoya la hipótesis de una diferencia estructural entre el norte y el sur. Mientras que la elasticidad mediana correspondiente de los 15 países al conjunto es de 0.79 (lo que significa que por cada punto porcentual de incremento del producto, el empleo se eleva $0.79 \%$ ), para los países del sur la cifra es de 0.52 comparada con 0.83 en los del norte. Ello indica que en éstos el crecimiento parece haber sido más intensivo en el uso de mano de obra, lo que contribuyó a generar puestos de trabajo más allá de lo que cabía prever por el crecimiento más dinámico en los años noventa.

Sin embargo, hay que interpretar con cuidado el significado de estas elasticidades. Como puede verse en el cuadro, tanto en los países del norte como en los del sur, algunas son muy elevadas. En Bolivia, Honduras, Paraguay y Venezuela las elasticidades superan a 1.00. Exceptuando parcialmente a Bolivia, se trata de situaciones en que las presiones de la oferta supe-
CUADRO 10

Tasas de crecimiento del PIB y elasticidad empleo, años noventa

\begin{tabular}{lcc}
\hline País & $\begin{array}{c}\text { Tasa de } \\
\text { crecimiento del PIB }\end{array}$ & $\begin{array}{c}\text { Elasticidad } \\
\text { empleo-producto }\end{array}$ \\
\hline Argentina & 4.7 & 0.30 \\
Bolivia & 4.0 & 1.35 \\
Brasil & 2.5 & 0.52 \\
Chile & 6.2 & 0.31 \\
Colombia & 2.6 & 0.42 \\
Costa Rica & 5.2 & 0.54 \\
El Salvador & 4.5 & 0.87 \\
Honduras & 3.0 & 1.63 \\
México & 3.2 & 0.97 \\
Panamá & 4.7 & 0.79 \\
Paraguay & 2.1 & 2.48 \\
Perú & 4.6 & 0.83 \\
República Dominicana & 5.0 & 0.70 \\
Uruguay & 5.0 & -0.17 \\
Venezuela & 2.0 & 1.75 \\
& & \\
América Latina (mediana) & 4.5 & 0.79 \\
Países del norte (mediana) & 4.6 & 0.83 \\
Países del sur (mediana) & 2.9 & 0.52 \\
\hline
\end{tabular}

Fuente: CEPAL (2000a, p. 66).

a La elasticidad se calculó dividiendo la tasa de crecimiento del empleo por la tasa de crecimiento del PIB.

raron la capacidad de la economía para generar puestos de trabajo en circunstancias de bajas tasas de crecimiento del PIB. Como consecuencia, el empleo "se creó" mediante el trabajo por cuenta propia y otras actividades del sector informal, y no porque los modelos económicos previeran el uso intensivo de mano de obra.

Como señalamos, el comportamiento del sector manufacturero es el factor principal que explica la diferencia en materia de creación de empleo en los países del norte y los del sur, y la industria maquiladora cumple una función importante, que explica las disparidades dentro de la industria. El cuadro 11 muestra la importancia que han tenido las maquiladoras. En realidad, en el decenio de 1990, fue el único tipo de manufactura que tuvo un crecimiento del empleo digno de mención. ${ }^{16}$ En algunos países, en especial México y la República Dominicana, a comienzos de los noventa estas empresas ya registraban un número importante de puestos de trabajo, pero la expansión principal se produjo en el transcurso de la década. En 1999, los empleos en la industria maquiladora representaban

16 Véase CEPAL (1997, p. 93, y 2001a, cap. 3). 
Empleo en la industria maquiladora, 1990-1999

\begin{tabular}{|c|c|c|c|c|c|}
\hline \multirow[b]{2}{*}{ País } & \multicolumn{3}{|c|}{$\begin{array}{l}\text { Empleo en industrias maquiladoras } \\
\text { (miles) }\end{array}$} & \multicolumn{2}{|c|}{$\begin{array}{c}\text { Empleo en industrias maquiladoras } \\
\text { como porcentaje del empleo en } \\
\text { la manufactura (1999) }\end{array}$} \\
\hline & 1990 & 1996 & 1999 & Total & Formal \\
\hline Costa Rica & 33 & 48 & $\ldots$ & $25^{\mathrm{a}}$ & $36^{\mathrm{a}}$ \\
\hline El Salvador & 2 & 38 & 45 & 11 & $\ldots$ \\
\hline Guatemala & 45 & 62 & $\ldots$ & $\ldots$ & $48^{\mathrm{a}}$ \\
\hline Haití & $\ldots$ & 20 & $\ldots$ & $\ldots$ & $\ldots$ \\
\hline Honduras & 18 & 76 & 120 & 32 & $\ldots$ \\
\hline México & 446 & 779 & 1197 & 16 & 28 \\
\hline Nicaragua & 0 & 8 & 20 & 16 & 36 \\
\hline República Dominicana & 130 & 164 & 191 & 37 & $\ldots$ \\
\hline
\end{tabular}

Fuente: Cálculos de los autores, sobre la base de estadísticas oficiales de los países.

a 1996.

de $10 \%$ a $40 \%$ del total de empleos en el sector manufacturero en la muestra de países del norte que figura en el cuadro. Asimismo, representaban hasta un $48 \%$ de los empleos en el sector formal. Como ellos dependen de las exportaciones a los Estados Unidos, el dinamismo reciente del mercado estadounidense fue decisivo para el desarrollo de esa industria; queda por ver cómo se comportará cuando las circunstancias sean menos favorables.

El gran crecimiento del empleo en las maquiladoras no significa que las industrias tradicionales de los países del norte no hayan sufrido el fuerte impacto de la apertura comercial y la modernización en el empleo como ocurrió en el sector manufacturero de los países del sur. En México, igual que en Argentina y Brasil, el aumento de las importaciones afectó a las industrias de uso intensivo de mano de obra como las textiles y de productos de cuero, y en el período 1990-2000 el número de puestos de trabajo en las industrias no maquiladoras se contrajo más de $10 \%$, con algún repunte a partir de $1997 .{ }^{17}$ Dadas estas tendencias comunes, el aumento del empleo en el sector manufacturero en los países del norte y su contracción en los del sur puede atribuirse principalmente a las maquiladoras.

A menudo se ha acusado a las maquiladoras de no cumplir con las normas laborales básicas, como el derecho de asociación, y de que ofrecen condiciones de trabajo deficientes, sin contribuir significativamente al desarrollo económico y social. ${ }^{18}$ Sin embargo, el sector incluye empresas muy diferentes y no es fácil generalizar.

\section{Recomendaciones de política}

En América Latina subsisten aún problemas importantes en materia de desarrollo económico, inversiones y productividad, pero en los años noventa se progresó en estos aspectos en comparación con los años ochenta. En cambio, se agudizaron los problemas relacionados con el empleo y la equidad: la generación de empleo fue poco dinámica, la calidad de los puestos de trabajo empeoró, y es probable que haya aumentado la desigualdad. Por lo tanto, los gobiernos deben concebir políticas orientadas expresamente a resolver estos pro- blemas. Los datos que hemos presentado acerca de las diferencias en cuanto a generación de empleo en el norte y en el sur de la región indican que, en cierta

\footnotetext{
17 Weller (2000a, cap. 5) y CEPAL (2001a, cap. 3).

18 Véase, por ejemplo, ort (1996, pp. 34-35). Para un análisis más detenido de la industria maquiladora, incluidos sus ventajas e inconvenientes, véase Buitelaar, Padilla y Urrutia (1999), y Buitelaar y Padilla (2000).
} 
medida, las políticas tienen que adaptarse a las características de cada país. ${ }^{19}$

Para la región en su conjunto, sin embargo, la política debe tener presente en general la necesidad de que la aceleración del crecimiento forme parte integral de toda estrategia encaminada a promover la generación de empleo. Para disminuir el desempleo y la desigualdad es indispensable que las tasas de crecimiento sean elevadas y estables. También son importantes las características del crecimiento. El nuevo modelo de desarrollo que se aplica en América Latina impone al sector privado la tarea de liderar la inversión, pero los gobiernos pueden ofrecer incentivos para que el crecimiento se base en un uso más intensivo de la mano de obra. De ahí la importancia de la creación de infraestructura, porque ofrece la doble ventaja de aumentar la capacidad de competencia del país y de generar un número importante de puestos de trabajo Las concesiones, como ampliación del proceso de privatización, son un mecanismo útil para lograrlo.

En cuanto a los países del norte, la industria maquiladora ofrece un gran potencial para mejorar cuantitativa y cualitativamente la situación del mercado de trabajo. Ya es posible observar diferencias importantes entre las maquiladoras en materia de tecnología, necesidades de capital humano, cumplimiento de la legislación laboral y otros aspectos, que indican que pueden desarrollarse, con consecuencias positivas para el empleo.

Reconocer este potencial ayudaría a superar la fútil confrontación entre quienes critican las deficientes condiciones de trabajo que predominan en las maquiladoras y sus partidarios que insisten en que la mayoría de las personas que trabajan en ellas carecen de alternativas satisfactorias de ocupación. Como los empleos que ofrecen las plantas maquiladoras corresponden al sector formal, lo más probable es que ofrezcan algunas ventajas comparadas con las actividades del sector informal. Sin embargo, a menudo se caracterizan por sus deficientes condiciones de trabajo y porque niegan el derecho a sindicalizarse. Combinando presiones externas para imponer el cumplimiento de normas básicas de parte de las empresas, como la obligación de aplicar códigos de conducta y la adopción de sellos de calidad social, con medidas internas para garantizar el derecho a sindicalizarse y el cum-

19 Esta sección se basa en Stallings y Peres (2000, cap. 7), y Altenburg, Qualmann y Weller (2001). Véanse otras propuestas de política para mejorar la situación del empleo en BID (1996), Edwards y Lustig (eds., 1997) y Tokman y Martínez (1999). plimiento de la legislación laboral, sería posible mejorar las condiciones de trabajo sin poner en peligro la competitividad de las empresas.

También podría mejorarse el sector de la maquila mediante una reforma que modifique gradualmente la base de su ventaja competitiva, de tal modo que ésta no sea más el bajo costo de los factores sino el conocimiento, tendencia que ya puede observarse en algunas redes de producción, particularmente en la zona fronteriza de los Estados Unidos y México y en Costa Rica. Otra mejora sería integrar la maquila más fuertemente en la estructura productiva del país mediante la creación de vínculos con las empresas medianas y pequeñas. Además de las reformas legales, esto indudablemente exige aumentar la competitividad de los proveedores nacionales.

En los países de América del Sur la industria maquiladora no es tan importante como el apoyo a las empresas pequeñas para que complementen la estructura productiva de uso intensivo de capital que predomina actualmente. Al concebir políticas de empleo para estas unidades, hay que distinguir las empresas medianas y pequeñas de las microempresas. Las primeras generalmente tienen potencial económico, de tal modo que el problema consiste en aumentar su competitividad. Aunque lo mismo podría decirse de algunas microempresas, muchas obedecen más bien a las necesidades de sobrevivencia que a un potencial empresarial relevante para mejorar las condiciones laborales. Por lo tanto, a la larga, los trabajadores de la gran mayoría de estas unidades deberían recibir mayor instrucción y capacitación, a fin de que puedan encontrar mejores oportunidades de empleo en otros sectores de la economía.

En otras partes del mundo se han aplicado dos métodos para mejorar la situación de las empresas pequeñas que podrían orientar provechosamente a los gobiernos de América Latina. El primero es la formación de agrupaciones de empresas que se dedican a la misma actividad con el fin de reducir el costo de los servicios a las empresas pequeñas. Entre los más exitosos cabe mencionar los creados en el norte de Italia. Las operaciones de crédito son particularmente costosas cuando es preciso negociar con numerosas empresas pequeñas y ha resultado viable la aplicación de un sistema de créditos colectivos, incluso en el caso de las microempresas (por ejemplo, el Banco del Sol en Bolivia o el Grameen Bank en Bangladesh). El mismo método ha dado buenos resultados en el caso de los pequeños productores agrícolas. La formación de agrupaciones puede prestar utilidad no sólo para el 
crédito, sino también para disminuir el costo de otros insumos y para la comercialización.

El segundo método para abordar la creación de puestos de trabajo productivos es que las empresas medianas y pequeñas se relacionen con empresas más grandes como proveedores A las empresas más grandes les conviene ayudar así a aumentar la competitividad de sus proveedores en pequeña escala, sobre todo en materia de información, tecnología, capacitación y financiamiento. En varios países asiáticos, incluso Japón, las relaciones con los proveedores han mejorado notablemente la viabilidad de las empresas pequeñas, pese a que en épocas de crisis tienden a llevarse la peor parte. Una variante de este enfoque es el modelo de producción por contrato, en virtud del cual una empresa comercializadora internacional adquiere los productos a empresas que los fabrican de acuerdo con sus especificaciones. En América Latina hay convenios de esta naturaleza, algunos con mayor éxito que otros.

Algunos expertos laborales han propuesto flexibilizar aun más el mercado de trabajo. ${ }^{20}$ A nuestro juicio, los mercados laborales ya son mucho más flexibles de lo que generalmente se piensa. Además, nos preocupa la posibilidad de introducir reformas radicales de dudosas consecuencias, tanto con respecto de los empleos nuevos como de la calidad de los existentes. Resulta muy inconveniente aplicar una solución general por las marcadas diferencias entre los mercados de trabajo de la región.

En vez de centrarse exclusivamente en la flexibilización, convendría que las autoridades buscasen sistemas para mejorar el funcionamiento de los mercados de trabajo. En todo caso, si un gobierno resolviera seguir adelante con la flexibilización, tendría que garantizar al mismo tiempo el acceso a un seguro de desempleo y, para facilitar la transición de un empleo a otro, no condicionar las prestaciones a la permanencia en una empresa determinada. Otra manera de mejorar el funcionamiento de los mercados de trabajo es proporcionar más información a los trabajadores y a las empresas a fin de reducir el período de búsqueda de trabajo y el desempleo friccional. Como estas medidas no eliminarán el desempleo estructural, habrá que combinarlas con las políticas de generación de empleo antes mencionadas.

Las iniciativas para estimular el empleo no reemplazan a las demás políticas sociales, sino que más bien

20 Véanse, por ejemplo, Guasch (1996), Burki y Perry (1997), Márquez y Pagés (1998) y Heckman y Pagés (2000). las complementan. Hay dos tipos de complementariedad, que se superponen. Uno es aumentar la capacidad de la fuerza de trabajo de adaptarse a las nuevas exigencias del mercado laboral, en especial en las circunstancias actuales cuando la región participa más de lleno en la economía mundial; en este caso, son fundamentales la educación y la capacitación, aunque la salud y la vivienda también son importantes. El otro se basa en la creación de redes de seguridad para prestar asistencia a los grupos vulnerables, es decir, a aquellos que no tienen acceso al mercado laboral o cuyos ingresos no les permiten mantener a sus familias. Ambos requieren un aumento del gasto social.

Tras la contracción del gasto social que se produjo durante la crisis del decenio de 1980, la totalidad de los países lo aumentaron en el decenio siguiente, algunos en proporción notable. ${ }^{21}$ Los recursos para elevar este gasto provienen de una o más de las tres fuentes siguientes: crecimiento más acelerado del PIB, aumento del gasto público como porcentaje del PIB, o incremento de la participación del gasto social en el gasto público total. Convendría que los países en que el gasto público representa una baja proporción del PIB acrecentaran esa proporción a fin de incrementar los servicios sociales; los demás probablemente tendrán que recurrir a uno de los otros dos mecanismos. Sin embargo, por lo que toca a la participación del gasto social en el gasto público total, varios países se aproximan al máximo políticamente viable. Quedan entonces tres posibilidades: utilizar más eficientemente los recursos existentes, aumentar el gasto público total, para lo cual habría que elevar los ingresos, o ampliar la participación del sector privado. Las tres opciones plantean problemas y cuál será la más conveniente variará según el país, de acuerdo con sus circunstancias y las preferencias de la sociedad en su conjunto.

No servirá de mucho aumentar y mejorar el gasto social si luego se restringe cuando sobreviene una crisis. Esto fue lo que sucedió en el decenio de 1980, y como el gasto social tiene una marcada tendencia procíclica, subsiste el peligro de futuras reducciones. Los gobiernos deben preocuparse de asegurar la protección del gasto social en épocas de crisis. Las pérdidas sociales de largo plazo, consecuencia de las crisis, a menudo nunca se recuperan. Puede ser que los niños que abandonan la escuela nunca regresen a ella, que los trabajadores que pierden su empleo pierdan experiencia de incalculable valor si tienen dificultades

\footnotetext{
21 Véase CEPAL (1999, cap. 4).
} 
para reincorporarse al trabajo, que las familias que pierdan sus viviendas tengan problemas por muchos años. Lo más probable es que los que se beneficien de la reactivación económica posterior no sean los mismos que resultaron perjudicados por la crisis.

Los servicios sociales deben asignar prioridad a mejorar y ampliar el acceso a la educación. Los gastos en la enseñanza tienen la doble ventaja de que contribuyen tanto a la competitividad como a una mayor igualdad, aunque a plazo relativamente largo. Gran parte de los problemas de distribución y de productividad a que hace frente América Latina obedecen a su gran disponibilidad de mano de obra no calificada, la que es producto de muchos años de deficiencias de la educación. Tiene suma importancia superar este legado de insuficiencia educativa. El tema ha sido ampliamente analizado, pero subsisten numerosas controversias y problemas relacionados con la forma de lograrlo. En el caso de la enseñanza básica, lo fundamental es mejorar la calidad; en la enseñanza secundaria, se trata de ampliar su cobertura y acceso. En cuanto a la educación superior, importa el acceso y la selección apropiada de los campos de especialización. Si se aumentara de manera notable el número de personas que se incorporan al mercado de trabajo habiendo cursado la enseñanza secundaria, se contribuiría a resolver simultáneamente los problemas económicos y sociales de la región.

En suma, es apremiante que los países de América Latina traten de resolver los problemas de empleo, que son el vínculo principal entre el desarrollo económico y el social. Los problemas que aquejan al empleo son también un peligro para las democracias de la región como se ha comprobado en varios casos. Las soluciones tienen que ser multifacéticas. En materia de economía, supondrán un incremento de las tasas de crecimiento y, por lo tanto, de la inversión; en el ámbito social, exigirán esfuerzos especiales en educación. Pero esto no basta, ya que también habrá que tratar de aplicar políticas destinadas a promover el empleo y prestar especial atención a los problemas de las empresas pequeñas e, incluso, de las microempresas.

Bibliografía

Altenburg, T., R. Qualmann y J. Weller (2001): Modernización económica y empleo en América Latina. Propuestas para un desarrollo incluyente, Macroeconomía del desarrollo, $\mathrm{N}^{\circ} 2$, Santiago de Chile, Comisión Económica para América Latina y el Caribe (CEPAL).

Balassa, B. y otros (1986): Toward Renewed Economic Growth in Latin America, Washington, D.C., Institute for International Economics (IIE)

Berry, A., ed. (1998): Poverty, Economic Reform, and Income Distribution in Latin America, Boulder, Colorado, Lynne Rienner.

BID (Banco Interamericano de Desarrollo) (1996): Progreso económico y social en América Latina. Informe 1996, Washington, D.C.

(1997): Progreso económico y social en América Latina. Informe 1997, Washington, D.C.

- (1998): Progreso económico y social en América Latina. Informe 1998-1999, Washington, D.C.

Bulmer-Thomas, V. (ed.) (1997): El nuevo modelo económico en América Latina: Su efecto en la distribución del ingreso y en la pobreza, México, D.F., Fondo de Cultura Económica (FCE).

Burki, S. y G. E. Perry (1997): The Long March: A Reform Agenda for Latin America and the Caribbean in the Next Decade, Washington, D.C., Banco Mundial.

Buitelaar, R., R. Padilla y R. Urrutia (1999): Industria maquiladora y cambio técnico, Revista de la CEPAL, $\mathrm{N}^{\circ}$ 67, LC/G.2055-P, Santiago de Chile, CEPAL.

Buitelaar, R. y R. Padilla (2000): Maquila, economic reform and corporate strategies, World Development, vol. 28, $\mathrm{N}^{\circ} 9$, Oxford, Reino Unido, Pergamon Press, Ltd.

CEPAL (1997): La brecha de la equidad. América Latina, el Caribe y la cumbre social, LC/G.1954/Rev.1-P, Santiago de Chile. Publicación de las Naciones Unidas, $\mathrm{N}^{\circ}$ de venta S.97.II.G.11.
(1998): Estudio económico de América Latina y el Caribe 1997-1998, LC/G.2032-P, Santiago de Chile.

(1999): Panorama social de América Latina, 1998, LC/ G.2050-P, Santiago de Chile.

(2000a): Estudio económico de América Latina y el Caribe 1999-2000, LC/G.2102-P, Santiago de Chile.

(2000b): Equidad, desarrollo y ciudadanía, LC/G.2071

(SES.28/3), Santiago de Chile.

(2001a): Estudio Económico de América Latina y el Caribe, 2000-2001, Santiago de Chile.

(2001b): Una década de luces y sombras. América Latina y el Caribe en los años noventa, Bogotá, Alfaomega.

Edwards, S. (1995): Crisis and Reform in Latin America: From Despair to Hope, Nueva York, Oxford University Press.

Edwards, S. y N. Lustig (eds.) (1997): Labor Markets in Latin America: Combining Social Protection with Market Flexibility, Washington, D.C., Brookings Institution Press.

Fernández Arias, E. y P. Montiel (1997): Reform and Growth in Latin America, All Pain, No Gain?, Working papers, N 351, Washington, D.C., BID.

Funkhouser, E. y J. P. Pérez Sáinz (1998): Mercado laboral y pobreza en Centroamérica, ganadores y perdedores del ajuste estructural, San José, Facultad Latinoamericana de Ciencias Sociales (FLACSO)/Consejo de Investigaciones sobre Ciencias Sociales.

García-Huidobro, G. (1999): La capacidad generadora de empleo productivo de la economía chilena, Serie reformas económicas, $\mathrm{N}^{\circ}$ 31, Santiago de Chile, CEPAL.

Guasch, J. L. (1996): La reforma laboral y la creación de empleo, el programa inconcluso en los países de América Latina y el Caribe, Segunda Conferencia Anual del Banco Mundial para el Desarrollo en América Latina y el Caribe, Santa Fe de Bogotá, Banco Mundial. 
Heckman, J. y C. Pagés (2000): The Cost of Job Security Regulation, Evidence from Latin American Labor Markets, NBER working paper, $N^{\circ} 7773$, Cambridge, Massachusetts, Oficina Nacional de Investigaciones Económicas.

Katz, J. (2000): Reformas estructurales, productividad y conducta tecnológica en América Latina, Santiago de Chile, CEPAL/FCE.

Krueger, A. O. (1978): Foreign Trade Regimes and Economic Development, Liberalization Attempts and Consequences, Cambridge, Massachusetts, Ballinger.

Krueger, A. O. y otros (eds.) (1981): Trade and Employment in Developing Countries. Individual Studies, vol. 1, Chicago, Illinois, The University of Chicago Press.

Krueger, A. O. (ed.) (1982): Trade and Employment in Developing Countries. Factor Supply and Substitution, vol. 2, Chicago, Illinois, The University of Chicago Press.

(1983): Trade and Employment in Developing Countries. Synthesis and Conclusions, Chicago, Illinois, The University of Chicago Press.

Londoño, J. L. y M. Székely (1997): Persistent Poverty and Excess Inequality: Latin America, 1970-1995, Working papers, №357, Washington, D.C., BID.

López, J. (1999): Evolución reciente del empleo en México, Serie reformas económicas, $\mathrm{N}^{\circ} 29$, Santiago de Chile, CEPAL.

Lora, E. y F. Barrera (1997): A Decade of Structural Reforms in Latin America, Growth, Productivity and Investment are not What They Used to Be, Working papers, $\mathrm{N}^{\circ} 350$, Washington, D.C., BID.

Lora, E. y M. Olivera (1998): Macro Policy and Employment Problems in Latin America, Working papers, $\mathrm{N}^{\circ} 372$, Washington, D.C., BID

Márquez, G. (ed.) (1995): Reforming the Labor Market in a Liberalized Economy, Washington, D.C., Johns Hopkins University Press.

Márquez, G. y C. Pagés (1998): Ties that bind, employment protection and labor market outcomes in Latin America, trabajo presentado en el seminario Employment in Latin America, What Is the Problem and How to Address It?, Cartagena de Indias, BID.

Mezzera, J. (1990): Informal Sector, as in PREALC, Working papers, $\mathrm{N}^{\circ} 349$, Santiago de Chile, Organización Internacional del Trabajo (OIT), Programa Regional del Empleo para América Latina y el Caribe (PREALC).

Montiel, N. (1999): Costa Rica: reformas económicas, sectores dinámicos y calidad de los empleos, Serie reformas económicas, $\mathrm{N}^{\circ} 26$, Santiago de Chile, CEPAL.

Morley, S. (2000): La distribución del ingreso en América Latina y el Caribe, Santiago de Chile, CEPAL/FCE.

OIT (1996): La situación sociolaboral en las zonas francas y empresas maquiladoras del Istmo Centroamericano y República Dominicana, San José. (1999a): Panorama laboral '99, Lima.

(1999b): Trabajo decente y protección para todos. Prioridad de las Américas, Memoria del Director General, XIV Reunión Regional Americana, Lima.

- (varios números): Panorama laboral de América Latina y el Caribe, Ginebra.

Ramírez, J. M. y L. Núñez (1999): Reformas estructurales, inversión y crecimiento: Colombia durante los años noventa, $\mathrm{Se}-$ rie reformas económicas, $\mathrm{N}^{\circ} 45$, Santiago de Chile, CEPAL.

Saavedra, J. y J. J. Díaz (1999): Desigualdad del ingreso y del gasto en el Perú antes y después de las reformas estructurales, Serie reformas económicas, $\mathrm{N}^{\circ} 34$, Santiago de Chile, CEPAL.

Stallings, B. y W. Peres (2000): Crecimiento, empleo y equidad. El impacto de las reformas económicas en América Latina y el Caribe, Santiago de Chile, CEPAL/FCE.

Tardanico, R. y R. Menjívar (eds.) (1997): Global Restructuring, Employment, and Social Inequality in Urban Latin America, Coral Gables, Florida, University of Miami.

Tokman, V. E. (1998): Empleo y solidaridad: los desafíos que enfrenta América Latina después del ajuste, L. Emmerij y J. Núñez del Arco (eds.), El desarrollo económico y social en los umbrales del siglo XXI, Washington, D.C., BID.

Tokman, V. E. y D. Martínez (1999): La agenda laboral en la globalización. Eficiencia económica con progreso social, Documento de trabajo, $N^{\circ}$ 94, Lima, Oficina Regional de la OIT para América Latina y el Caribe.

Tuman, J. P. (2000): Labor markets and economic reform in Latin America: A review of recent research, Latin American Research Review, vol. 35, $\mathrm{N}^{\circ}$ 3, Washington, D.C.

Turnham, D., C. Foy y G. Larraín (eds.) (1995): Social Tensions, Job Creation and Economic Policy in Latin America, París, Organización de Cooperación y Desarrollo Económicos (OCDE).

Weeks, J. (1999): Salarios, empleo y derechos de los trabajadores en América Latina entre 1970 y 1998, Revista internacional del trabajo, vol. 118, $\mathrm{N}^{\circ} 2$, Ginebra, OIT.

Weller, J. (2000a): Reformas económicas, crecimiento y empleo, los mercados de trabajo en América Latina durante los años noventa, Santiago de Chile, CEPAL/FCE.

Weller, J. (2000b): Tendencias del empleo en los años noventa en América Latina y el Caribe, Revista de la CEPAL, N 72 , LC/G.2120, Santiago de Chile, CEPAL, Publicación de las Naciones Unidas.

Williamson, J. (1990): Latin American Adjustment: How Much has Happened?, Washington, D.C., IIE.

(1993): Democracy and the 'Washington Consensus', World Development, vol. 21, № 8, Oxford, Reino Unido, Pergamon Press. 